\title{
Theory and Method of Language Contact
}

\author{
Jianya Zhang \\ College of Liberal Arts \\ South China Normal University \\ Guangzhou, China 510006
}

\author{
Weiming Peng* \\ College of Liberal Arts \\ South China Normal University \\ Guangzhou, China 510006 \\ *Corresponding Author
}

\begin{abstract}
This paper examines the studies and scholars concerning language contact, sorts out the mainstream theories of the theory of language contact and highlights relevant differences. With timeline, foreign studies fall into pre-theory phase and theory-development phase. And Chinese studies could be divided in theory construction and methodology.
\end{abstract}

Keywords-language contact; mainstream theories; research methods; literature review

\section{INTRODUCTION}

In early stage, historical comparative linguistician tends to pay more attention to the differentiation of the language. According to study the relative questions of the language, it would reconstruct or construct the primary language. After the middle of the 19th century, scholars began to notice that the evolution of language was not limited to the phylogenetic differentiation. The evolution and development of language has been interdependent. There is language contact between kin languages and non-kin languages. In this dissertation, the author classifies comparatively representative theories of language contact. Foreign studies began earlier. And research time is longer. With timeline, the studies in China start later. Also, the research time is short. Therefore, it takes the classification with the category of research.

\section{THE STUDY OF WESTERN SCHOLARS}

\section{A. Study in Pre-theory Phase}

In the middle of the 19th century, the limitations of the historical comparative method, which ignored the interplay between languages, had become more and more obvious. People's understanding of the interrelationship of languages and the contact relationship of languages has sprouted. In 1872, Johannes Schmidt proposed "wave theory" in the development of language. Schmidt restored the phylogenetic tree theory of August Schleicher to the geographical representation of language. He found that geographically adjacent different languages didn't oppose each other or supplement each other. Instead, they intersected with each other. And it had produced common features under the influences of each other. Since then, "Wave Theory" has been regarded as the germ of the theory of language contact.

The early attention to language contact is hybridization. Van Name (1869-1870) in the United States was the first one to conduct scientific study of mixed language. He studied
Creole respectively, which was developed based on highlevel languages of French, German, Spanish and English. Also, he pointed out the common characteristics. He believed that Creole was developed from pidgin. [1]

Bloomfield's "Language" discussed some of the borrowings in Western languages at that time. And he believed that "cultural borrowing", "intimate borrowing" and "dialect borrowing" were borrowing patterns related to language contact. [2]

The Russian linguist Trubetzkoy proposed the sprachbund theory in 1928 . The sprachbund refers to the fact that geographically adjacent non-relative languages may have certain similarities in phonology, vocabulary and grammar. [3] In his opinion, with language contact, modern Indo-European languages have sprachbund. Mutual borrowing of languages can also lead to phonological correspondence. We could have common examples such as the sprachbund of Balkan Peninsula. Similar to the language of the Balkans, the languages of East Asian and Southeast Asian also have the phenomenon of sprachbund, such as Zhuang Dong language. From the perspective of core words, they have more close kinship with the Austronesian languages. They are consistent with the unnatural tone of other Austronesian family in the East Asian mainland. However, there is a tone in the Zhuang Dong language that borders on the Chinese language in southern China, which is also a part of the sprachbund.

From the middle of 19th century to the middle of the 20th century, it is the embryonic stage of the linguistic view that can influence each other between languages. Also, it is the stage of discussion on theories related to the initiation of language contact. The research mainly centers on the phenomena of linguistic interaction. It makes macro-analysis

\section{B. The Stage of Basic Theory}

Since the 1950s, the study of language contact has become increasingly prosperous. Related theories such as bilingualism, hybridization and linguistic interference have also been enriched. In 1953, Weinreich's monograph "Language in contact: Findings and Problems" was published, marking the formal establishment of contact linguistics. "Language in contact" studies language contact and bilingual phenomena. The dissertation discusses the linguistic interference mechanisms by which bilinguals in Romanian and German, as well as their native speakers of 
English and Hindi. [4] Haugen, an American linguist, also explored bilingualism and linguistic borrowing. In 1950, "The Analysis of Linguistic Borrowing" was published in the magazine of "Language". And he classified loan words into loanwords, hybrid word and loanshif words according to the difference of the morpheme substitutions in the borrowed forms. [5]

In his article "Diglossia," published in 1959 by Ferguson, "double language" was defined as two or more variants that use the same language in different situations. [6] He found that there were two kinds of linguistic variants with different functions in some areas. One is the "lower" variant ("L"), and the other is the "advanced" variant ("H"). Almost everyone could say L. However, we have to learn H through formal education.

W. Labov is one of the representatives of social linguistics. The study of linguistic variation pioneered by him flourished in the 1960s and 1970s. In 1964, his doctoral dissertation used sociological sampling and statistical methods to investigate the language variable of the New York department store. And then, he made quantitative statistics of language variable (manner of articulation) and social variable (pronunciation age, class, gender, etc.). The results show that linguistic variables are related to social variables. That is to say, linguistic variables will change as the social variables change. [7]

The first International Conference on Language Contact and Language Conflict was held in 1979 in Brussels, Belgium. Since then, contact linguistics has gradually become a new field of linguistic research. The important linguists that emerged during this period were Trudgill, Thomason, Kaufman and others.

Inspired by W. Labov's sociolinguistic research method, Trudgill conducted a social survey of the target language. He found that phonetic variation was associated with social class and gender. His book "Dialects in Contact" specifically studied the contact problems between different dialects in English. [8] He pointed out that language diffusion was related to demographic parameters. People from other places prefer to communicate with the persons in larger cities. For example, the percentage of Norwegians willing to communicate with Britons is more than 30 to 40 times that of other small cities. Thomason and Kaufman explored language contact, Creole and language change. [9] Language contact is interpreted as a state, which is the driving force or condition to promote language change. And it is not the process of language change. In another monograph of the language contact of Thomas, there was also in-depth explanation of the mechanisms triggered by language contact, the mixed language and Creole. In her opinion, the social factors were the decisive factors that lead to language contact. [10]

From the perspective of sociolinguistics, to study the problem of language contact would be relatively common phenomenon at that time. We can study linguistic variation with a number of sociolinguistic quantitative statistical analysis methods. It can objectively reflect the overall linguistic characteristics. However, there are limitations. The internal differences of linguistic variability can easily be obscured by the average value of the statistics. Therefore, to study the issue of language contact should be combined with internal structure variation and external factors. After all, the evolution of language is caused by the interaction of the internal and the external. And they should be complementary to each other.

\section{RESEARCH OF CHINESE SCHOLARS}

Since the 1950s, Chinese language workers began to notice the phenomenon of language variation caused by language contact when censoring national languages. By the 1970 s and 1980s, there had great development in the study of language contact. The subjects of the study mainly involve Chinese and ethnic language contact, Mandarin and dialect contact and dialect-dialect contact. Some improvements have been made in the construction of the theory and method of language contact.

\section{A. The Stage of Theoretical Construction}

In the 1960s, Chinese American scholar Wang, William S.Y. put forward the theory of "Lexical-diffusing theory" [11]. It put forward the query and retort of "Neogrammarians' theory" in Neogrammarians and the gradual change of phonetic value and lexical mutation in the process of sound change. He examined the sound changes in Chinese dialects and American English. He believed that the process of sound change referred to "sound mutation and gradual change of vocabulary". The exception in the evolution was the remnants left by the sound change. Since then, Wang, William S.Y. has further proposed "double diffusion theory". With the tonal evolution of Tiechiu Dialect as evidence, it has demonstrated the interaction between the inherent evolution of language and the evolution triggered by language contact. It emphasizes the coexistence of languages. Since then, on this basis, Xu Tongqiang and Wang Hongjun have done a lot of field investigations to thoroughly study the phenomenon of literary versus colloquial distinction. They put forward the theory of overlapped sound change to explain the mechanism of dialect contact. And it is the innovation based on lexical-diffusing theory. [12] Based on the rich literary versus colloquial distinction of Wenxi dialect, Shanxi, Wang Hongjun described and analyzed the process and characteristics of overlapped sound change caused by the entry of phonetic system of foreign authoritative dialects in details. It revealed the difference of sound change unit, the process of sound changes and the nature of sound changes in terms of overlapped sound changes and lexical-diffusing sound change. [13]

Xing Gongwan explored the phonological correspondence between Chinese and Tai loan words to prove the glossogenetics relationship. And it also proposed a method to search for deep-layer correspondence. It is different from comparative approach of Indo-European language. This method is regarded as comparative characteristics of Sino-Tibetan family. [14] Subsequently, Chen Baoya studied Dehong Chinese and Dai language. He discussed the etymological relationship of Vietnamese transcription of the borrowed Chinese words (Dong and Tai 
language). On the basis of the theory of sprachbund of Trouteskoye, Chen Baoya proposed "Rank analysis", which claims that language contacts have rank difference but no boundary. With the Curve Theory of R anks, it examined the performance of words in different languages. And they are semantically or phonetically related. [15]

\section{B. The Types of Research Methods of Language Contact}

1) Comparative studies: It is a relatively traditional method to study the language contact with the comparative approach. For example, in the mandarin and dialect contact, we could have the horizontal comparison of dialect materials and that of mandarin. Also, we could have the vertical comparison of dialects and historical materials. Through the comparison, we could make the summary of changes of the dialect or mandarin language system. Hu Mingyang (1978) examined the changes of Shanghainese over a hundred years from the middle of 19th century to the middle of 20th century. [16] Dai Qingxia (2005) made the comparison among related native dialects. And it took the Aizhai dialect of Miao language in west of hunan province as the reference, and he analyzed lexical changes of Xiao po liu Miao language affected by the Chinese. [17]

2) Quantitative study: With quantitative study, we could have the quantitative analysis of pronunciation and vocabulary in the language system. Then, we could sort out the relatives or differences in different dialects or national languages. It would provide reference for quantitative analysis of contact study. The current common methods of quantitative study are:

The first, it is the correlation coefficient statistics. Based on the words, Chinchuan Cheng uses the "Pearson correlation" and "non-weighted averaging method" to calculate the lexical relationship of Chinese dialects. At the same time, it would provide dialectal division. [18] Wang, William S.Y. and Shen Zhongwei used morpheme to make quantitative study of the lexical relationship among the 33 local dialects in Wu dialect. [19] Lu Zhiji used 2722 words of 17 Chinese dialect spots as the statistical objects, arranged the data of initial consonants and vowels distribution, and used correlation analysis and cluster analysis to make measurement description of the closeness and classification of each dialect. [20]

Second, it is weighted mean. With weighted mean, You Rujie and Yang Bei could make quantitative study on approaching rate of vocabulary of Cantonese, Shanghai dialect and mandarin. [21] The new method has three characteristics. We could use the weighting method to statistics the similarities and differences of different dialects. And it would take the word frequency as the weight. Based on the core morpheme, we could make the comparison of similarities and differences of the words. Then, we could make weighted statistics. Also, we should make multi-person test of oral speech intelligibility of the dialect vocabulary.

Third, it is edit linguistic distance. Linguistic distance refers to the similarity of different languages or language variants. The closer the linguistic distance is, the higher the similarity between languages is. Linguistic distance also could be known as edit distance. Russian scientist Vladimir Levenshtein put forward the concept of levenshtein distance in 1965. And it was initially applied to DNA analysis. Kessler first proposed that we could use edit distance to calculate the linguistic distance between dialects. [22] Edit distance can objectively reveal the relationship between the languages through quantitative study. In recent years, it is used to calculate linguistic distance of dialects or the study of linguistic typology. Zhang Jisheng (2015) used the edit distance to calculate the linguistic distance of vocabularies of five dialect spots in $\mathrm{Wu}$ dialect from the perspective of segment. [23]

3) The study of acoustic experiment

Bei Xianming applied the method of sound pattern to the study of dialect contact. Through the acoustic experiments of vowel pattern and tonal pattern, Bei Xianming investigated the phonetics contact of Hunan dialect and Gan dialect. He pointed out that dialect contacts would cause three modes of "transition", "overshot" and "reverse" of speech. [24] According to the acoustic distribution pattern, the most appeared was "transition", the less was "reverse". And the "reverse" mode mainly occurs in low or highly marked phonological units. In this paper, it draws lessons from three stages of dialect contact (pidginization-creolizationdecreolization).

\section{CONCLUSION}

To sum up, the scholars have studied the language contact for more than 150 years. The study of language contact with western languages as the main research object has made great progress. A batch of theoretical achievements with certain height has come out in succession. The research on Chinese language contact started late, and the research enthusiasm increased greatly in recent years. It is worth mentioning that the scholars could use the method of mathematical statistics and the method of experimental phonetics to carry out acoustic research methods such as sound pattern. And it could provide mathematical reference for the qualitative research of language contact. However, some aspects are not perfect. Combining with the knowledge of statistics, sociology, phonetics and computer science, they would be helpful to the research of language contact. And the knowledge could assist qualitative research methods.

\section{REFERENCES}

[1] Addison Van Name. "Contributions to Creole Grammar", Transactions of the American Philological Association, Vol.1,1869, pp.123-167.

[2] [US] Leonard Bloomfield. "Language", translated by Yuan Jiahua, Beijing: Commercial Press, 1997, pp.586.

[3] Qu Changliang. "Jakobson Phonology Theory: Opposition, Distinctive Feature, and Phono Morphology", World Book Publishing Company, 2015, pp.170-173.

[4] [US] Uriel Weinreich. Languages in Contact: Findings and Problems, Mouton Publishers, The Hugue, 1968, pp.7-106.

[5] [US] Einar Haugen. "The Analysis of Linguistic Borrowing", "Language", Vol.26, No.2, 1950, pp.210-231. 
[6] [US] Charles A.Ferguson. "Diglossia", "Word", Vol.15, 1959, pp.325-340.

[7] [US] William Labov. The Social Stratification of English in New York City, Columbia University, Ph.D., 1964, pp. 64-211.

[8] [US] Peter Trudgill. Dialects in Contact, Basil Blackwell Ltd, 1986, pp.39-82.

[9] Sarah G.Thomason and Terrence Kaufman, Language contact, creolization, and genetic linguistic, Berkeley University of California Press, 1988, p.34.

[10] (United States) Sarah G. Thomason, Language contac: an introduction, introduced by Wu Fuxiang, World Book Publishing House, 2014, p. 46.

[11] Wang, William S.Y. "Competing Changes as a Cause of Residue", Language, Vol.45, No. 1, 1969, pp.9-25.

[12] Xu Tongqiang, Wang Hongjun. "Wenxi dialect tone in Shanxi", "Linguistic Research", 1986(4).

[13] Wang Hongjun. "Historical linguistics methodology and case study of the history of Chinese dialects phonology", Beijing: Commercial Press, 2014, pp. 314-323.

[14] Xing Gongwan. "Deep-layer correspondence in the comparative study of Chinese and Taiwanese", "Minority Languages of China", 1993(5).

[15] Chen Baoya. "On Language Contact and sprachbund — Interpretation of the Etymological Relationship between Chinese and Vietnamese (Dong Tai Language)", Beijing: Language Publishing House. 1996, pp. 141-152.

[16] Hu Mingyang. "Some changes of Shanghai dialect in a hundred years", "Studies of the Chinese Language", 1978(3).

[17] Dai Qingxia. "Language contact and language evolution - A case study of Xiao po liu Miao language", "Linguistic Sciences", 2005(4).

[18] Cheng ChinChuan, "A Quantification of Chinese Dialect Affinity", Studies in the Linguistic Sciences, Vol.12, No. 1, 1982, pp.29-47.

[19] Wang, William S.Y., Shen Zhongwei. "Measurement of dialect relations", "Studies of the Chinese Language", 1992(2).

[20] Lu Zhiji. "Measurement of the relationships between Chinese and dialects", "Social Sciences in China", 1987(1).

[21] You Rujie, Zou Jiayan. "Sociolinguistics", Shanghai: Fudan University Press, p.97-103.

[22] [US] Brett Kessler. "Computational Dialectology in Irish Gaelic". Proceedings of the European Acl-67 Dublin Association for Computational Linguistics, Vol.5, No. 9, 1999, pp.2061-2063.

[23] Zhang Jisheng. "A study of correlation between linguistic distance and mutual intelligibility among $\mathrm{Wu}$ dialects in light of feature specification", "Studies of the Chinese Language", 2015(1).

[24] Bei Xianming. "Sound patterns in dialect contact", doctoral dissertation of Nankai University, 2008, pp. 67-81. 